$\begin{array}{cccc}S \text { sciendo } & \text { International Conference KNOWLEDGE-BASED ORGANIZATION } \\ \text { Vol. XXV } & \text { No } 1 & 2019\end{array}$

\title{
IMPROVING THE QUALITY AND EFFICIENCY OF HIGHER EDUCATION SYSTEMS BASED ON THE KNOWLEDGE-MANAGEMENT APPROACH
}

\author{
George BUCĂȚA*, Marius Alexandru RIZESCU** \\ *"Lucian Blaga" University, Sibiu, Romania \\ **6“Nicolae Bălcescu” Land Forces Academy, Sibiu, Romania \\ george.bucata@yahoo.ro,mariusrizescu@yahoo.com
}

\begin{abstract}
The complexity of phenomena in modern society requires rich knowledge and practical abilities. Also, the speed at which information circulates in immense volume inhibits the ability of the interpreter to interpret it in a timely manner. Contemporary society is characterized by dynamism, by continuous renewal. It can only be known by personal, variable, and largely subjective, symbolic interpretations. The transition from knowledge as an ensemble of knowledge, information, data, to knowledge as a set of competencies determines a shift of emphasis in education, from ex-cathedra exposure to learning through experience/practice, transmission and memorization information (information), skills training, and skills. There is a need for the formation of individuals capable of analyzing concrete, new situations, and responding appropriately using logical thinking, problem solving, critical thinking, and divergent thinking skills.
\end{abstract}

Keywords: educational quality, educational efficiency, higher education system, knowledge management, educational knowledge management

\section{Introduction}

Referring to the "university of the future", we can highlight the following factors that support the university's perennial reasons for which the university is considered a stable institution of the future, occupying a central place: the university is multidisciplinary; university requires permanent education; the university integrates science, teaching and production; the university treats the information accordingly; the university has a special rhythm of work., the university is multidisciplinary [5].

As the future is in favor of more disciplines and broader specialization, it is good to have in each education system two ways of exploring a field: as a profession and as a discipline. The university does not award a professional degree, but a multifaceted license in a field of science:

- the University requires permanent education: everything that is particular in the concept of university, specific or restricted as a sphere of application becomes general, broad and comprehensive. In the future, there is the question of generalizing university education. The university becomes a place you are tied to and periodically recurring, which keeps track of both training and training needs;

- the University integrates science, teaching and production: the university is considered to be an institution able to connect with the other research and production factors essential to tomorrow's society. The fact that the university has classrooms gives it supremacy or ascendancy. The lab is its modern and significant part, where 
universities are less likely to adapt to the new; [8]

- the University treats the information properly: the University reveals a new vocation when it promises to be a documentary center suitable for the mass influx of information. The existence of computing centers allows universities to investigate the so-called problem of finding information;

- the University has a special rhythm of work, rhythm sometimes criticized for its sluggishness, sometimes envied for the absence of instant tasks. Published works, speech deliveries, communications, discoveries could only be completed after decades of toil. We can ask ourselves in favor of the future. The university is a longterm institution. It has in its structure the necessary time to pursue the fundamental objectives of society as the progress of science. The type of human activity will be closer in the future to the type of university investigation. For Romania, it becomes essential for the realization of the information society, but under the current conditions it must take place with the first objectives of the knowledge society. It is wrong to say: first the information society and then the knowledge society.

Education in the knowledge-based society promotes a new model of creative school, which must be projected at a superior, innovative level, in accordance with the structures of an open society, engaged in achieving a permanent social competition, on the basis of value: a) economic - market; b) political democracy; c) cultural - computerization through the selection and processing of essential information and their improvement in the network, in multiple relationships of interaction and interdependence; d) community administrative decentralization for the optimal valorization of resources in territorial and local contexts, based on general, determined macro structural, global and national requirements, scientifically legitimate (political, economic, legal, pedagogical, etc.); e) natural - the affirmation of ecology as a positive selfregulation factor of the relations between man and technology - the natural environment (physical, geographical, climatic, demographic, etc) [2].

\section{Knowledge in the educational environment}

The generation and exploitation of knowledge have become vital sources of welfare growth globally. Knowledge is at the same time the central element that determines competitiveness, and as such the states of the world, especially the developed ones, have engaged in its systematic generation, developing increasingly sophisticated national systems and international interactions [6]. The emphasis on globalization has led to an increase in the importance of international collaboration, the exchange of explicit knowledge, and the creation of strong international science communities, without, however, reducing the importance that the complex of local factors has in adapting and capitalizing on knowledge [13]. In this collaborative and competitive environment at the same time, the significance of excellence has grown exponentially. Entities and individuals attaining this level become extremely valuable, having the capacity to attract resources and influence both the scientific environment and the socio-economic systems. This is also why developed countries are making efforts to attract scientists and engineers with outstanding performance and at the same time to reach critical mass of research in strategic areas [3].

In a knowledge-based society, changes are more consistent and follow a steady pace. And these changes are concentrated in a number of major directions which, although they cannot be considered exhaustive, give a clear enough picture of the challenges ahead and the impact they will have on the existence and activity of organizations [18]. 
The structure of the knowledge-based economy evolves from resources, processes, products and distribution systems material to resources, processes, products and symbolic distribution systems. In such an economy, which relies heavily on the conversion of intangible goods rather than material into high value added products and services, products and services sold and consumed in all the world's successful markets, the first countries to modernize their system of production will undoubtedly enjoy the firstmover advantage, as it did with those countries that made the first industrial revolution [4]. An essential element of this change is the change in the emphasis placed on the various components of the capital stock in the economy. Thus, natural capital (natural resources and the environment), a largely non-regenerative resource, and capital produced by man (physical capital and financial assets), short-term renewable capital, are increasingly substituted by human capital and social capital, virtually inexhaustible resources [10].

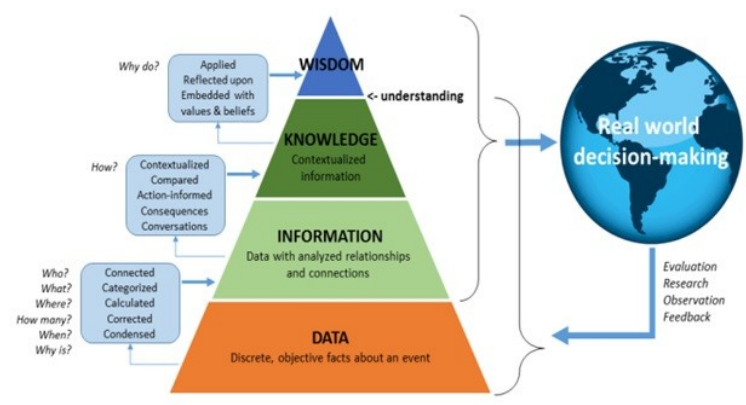

Figure 1: DIKW pyramid: data to wisdom, flow of knowledge and information (self creation)

Given that the decentralization of the education system is becoming more and more intense, the effectiveness of knowledge management increases substantially if the educational institution proves to be concerned about carrying out a careful analysis of the external environment, thus providing others with information on their own work [12]. So the educational institution will be perceived as:
- useful for potential clients;

- the competence to produce educational products and services;

- ensuring the quality of the educational services;

- authority in the respective educational field;

- willing to participate together with other schools to improve the results in the field;

- run several projects at the same time;

- autonomy in the realization of educational services and products offered to the market; - authenticity of performance [17].

Actions aimed at improving the school management system, as knowledge is integrated into this system, mainly aim at: [15]

- conceiving the management system of the education unit and redesigning it on rigorous scientific basis;

- the remodeling of the school development strategies, corresponding to the requirements of the current stage of development of the Romanian society, characterized by the transition to the market economy and the restructuring of the national economy;

- completion and modernization of managerial tools;

- the decisive role of strategic and tactical decisions, risk and uncertainty and economic decisions in rationalizing the decision-making process and in accelerating profitability;

- the need to shorten the duration of the circuit within the educational managerial system, so that the strategies and the policies concretized in the educational products and their organization and "marketing" on the educational services market are rapidly operationalized;

- training of educational managers according to the requirements of a European education. 


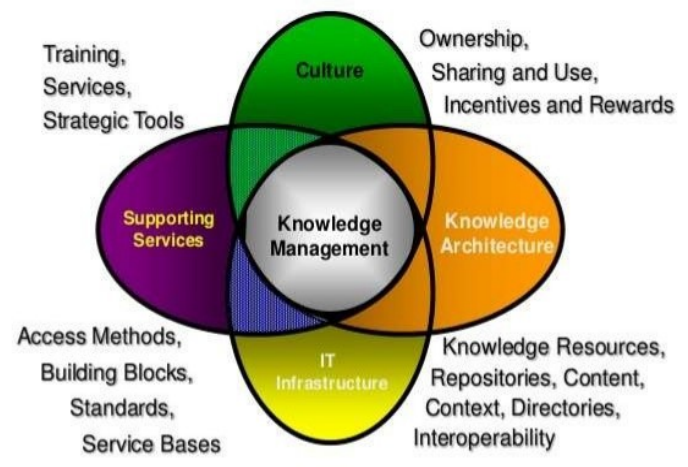

Figure 2: Knowledge Management Success Factors (self creation)

Order and discipline characterize an educational management system in addressing and solving the problems of the educational organization [16]. Therefore, it is necessary for the school manager to provide a discipline that reflects the essence of the educational processes involved, differentiated according to their nature. For example, for teaching - learning, discipline means a perfect fit of the lesson in the work program, a thorough application of teaching didactic methods, aiming at achieving the standards of student training throughout the lesson [7].

A major dimension of the discipline, with many decisional and operational implications, is the responsibility of each employee, teachers' teams as a whole, and student collectives. Increasing discipline is an essential milestone of an effective educational management system that is indispensable for achieving the expected performance [9]. Another important indicator of the efficiency of the educational organization's management is the dynamism of the conception and realization of the actions, the entrepreneurial spirit shown by both the leaders of the institution as well as the teachers and the other employees. The accelerated pace of change in all areas of activity, the requirements of the market economy, require an increase in the speed of reaction from all the actors who carry out their work in a learning unit. Initiative and dynamism have an increasing influence on the effectiveness of educational decisions and actions, being decisive in the achievement of a training that meets the quality standards at this time of EU integration in Romania, a period that is based on the construction of a competitive type in which rapid technical progress, the multitude of international contacts and profit making will be the main targets of the economic and social development of our country [1].

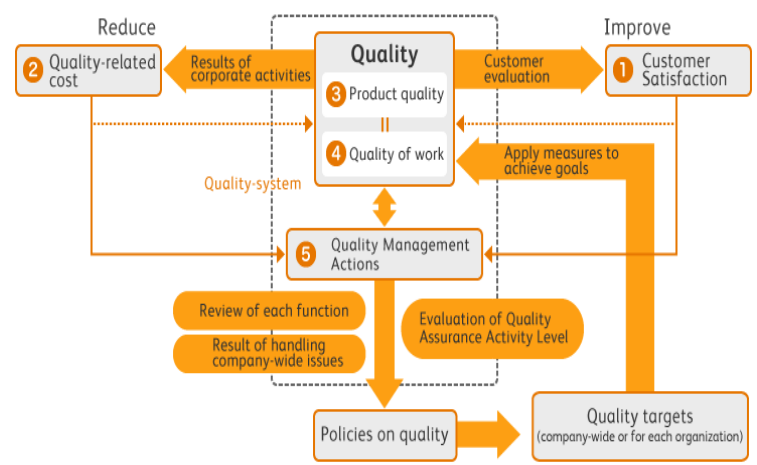

Figure 3: Quality Assurance Activities process (self creation)

\section{Quality from higher education perspective}

We can explore education from a quality perspective in 5 ways: [11]

- It is an education system that results in a competent graduate in the field for which it has been formed, taking into account the fact that through competence we understand a set of knowledge, abilities, attitudes / values. In other words, the competent graduate holds information, which he is able to apply in concrete situations, according to a set of principles. Although not easy, the easiest in an education system is to obtain the quality of information: accurate, correct, current. When we talk about the quality of skills that make up competence is harder. Here we need a lot of practice and standards as close as possible to what happens in a profession, as well as an emphasis on transversal skills (communication, logic and thinking, learning to learn, developing 
personal, creativity, etc.). By far, however, the most difficult is to achieve quality at the level of attitudes/values. Beyond the relativism of values, we can anchor ourselves in the ethical codes of professions, but we have many professions and professions that do not have an ethical code. In addition, when it comes to moral education, it does not matter as a method of teaching about, but the personal example matters.

- The quality education system produces performers for the labor market and for life: It is appropriate to make a distinction between competence and performance. A competent graduate becomes performer when exercising those skill sets in a practical, real context. Its performance level may vary depending on the day, the difficulty of solving the problem, its experience in the field, etc. Therefore, I think it is rather the role of initial training to create competent graduates and rather the continuous training to create successful graduates. There are obvious exceptions: Higher education would be desirable to generate both competence and performance, and ongoing training to familiarize someone with a new occupation is more focused on skills training.

- Quality education is a right of every child: the right to education is linked to the right to personal health and the environment at home and at school, as well as access to a minimum of resources. A sick and poor child will face delays and difficulties in development and learning, compared to a healthy, well-nourished, well-dressed child who has positive stimuli around him (a person who reads him, visits, excursions, etc.) small ages. At a more specialized level, the content of quality learning is relevant to the objectives of education in a country so that the graduate can function in a positive way in society. The way teachers are trained is a determining factor in the quality of education that a child enjoys.

- There is a set of indicators that, if respected, guarantee both the quality of education and the repeatability of the same quality level regardless of the school in which the pupil learns: quality assurance systems contain standards and indicators, but deep ones also contain a complex and complex vision of the world and life. Most of these systems have been designed for products and services, and then they have been or are trying to be translated into education. The reason for this is unquestionable, but often fails to write procedures and make a set of papers as they should, but very different from real action. The causes of this type of schizoid action are multiple (among them the double standard I mentioned earlier), but I would only analyze the lack of understanding of the philosophy on which the quality assurance system is based. Some are cumbersome, some are utopian and some are inadequately adapted to the education sector. The assumption in the background is that nothing is perfect, but everything is perfect. It's never too late to correct a mistake. Hence neither the papers nor the actions can be perfect. It does not fit an oppressive system, where the mistake is punished immediately and no selfimprovement is offered. If we honestly acknowledge that we are wrong and we really accept the situation as it is, we have a chance to change something and improve it. - The quality of learning is the quality of life: for thousands of years we have been striving for humanity to find a way of education as good as we want the generation that comes after us to have a good life. In school and in education humanity should put all the best: soul, resources, passion, care, birds, etc., because it is the most beautiful and important gift (besides the genetic one) that we can do to ourselves per se. If everyone involved in education gives their best at every learning opportunity, then the result is as good as possible. And it will be immediately seen in the respectful behavior on the street, in public transport, in the public spaces, it will be seen in the professional environment, it 
will be seen in the way we decorate not only the houses but, above all, the interior of the being.

In terms of quality, universities that will focus primarily on research will be able to define rules other than those centered on education or vocational education [19]. The differentiation of higher education institutions will stop at the gate of universities if they do not have autonomy in defining the content of the posts they have [14].

\section{Conclusion}

Permanent change is a reality that organizations need to become accustomed to, with the awareness that change is faster and more random. In this context, no education unit can deny the role that each employee's performance has in the longterm success of their work, and this performance is no longer determined by factors such as loyalty or job security but by personal goals. The school's internal success is essential to the success of the school outside. Ultimately, success means getting everyone's agreement on the goals and realizing them. Given the variety of positions in an organization, as well as the frequent changes in the roles and responsibilities of employees, achieving success is a more difficult issue and therefore, it is not necessary to set goals at the state of good intentions statement. Therefore, management should have a procedure in this respect, namely a performance management process. Those organizations that practice performance appraisal, however, face several difficulties, some resulting from the complexity of implementing and using the system, others from the lack of awareness of some rather delicate issues. Thus, in many organizations, performance of the performance appraisal system is required for human resources. In this article, the main methods used were the analysis and the comparison.

\section{References}

[1] Botha, R.J. (2011), The managerial role of the principal in promoting teacher professionalism in selected Eastern Cape schools, Africa Education Review, Vol. 8 No.3, pp. 397-415.

[2] Ceobanu, C., \& Boncu, S. (2014), The Challenges of the Mobile Technology in the Young Adult Education, Procedia Social and Behavioural Sciences, 142, 647-652.

[3] Day, C \& Sammons, P. (2013), Successful Leadership: a review of the international literature, CfBT Education Trust.

[4] Draghici, A., Popescu, A., Fistis, G., \& Borca, C. (2014), Behaviour Attributes That Nurture The Sense of E-Learning Community Perception, Procedia Technology, 16, 745-754.

[5] Hubackova, S., \& Golkova, D. (2014), Podcasting in Foreign Language Teaching. Procedia Social and Behavioural Sciences, 143, 143-146.

[6] Kanaan, R., \& Gharaibeh, A. (2013), The Impact of Knowledge Sharing Enablers on Knowledge Sharing Capability: An Empirical Study on Jordanian Telecommunication Firms, European Scientific Journal, 9 (22), 237-258.

[7] Klapper, R., \& Tegtmeier, S. (2010), Innovating entrepreneurial pedagogy: Examples from France and Germany. Journal of Small Business and Enterprise Development, 17, 552-568.10.1108/14626001011088723.

[8] Louis, K.S., Leithwood, K., Wahlstrom, K., and Anderson, S. (2010), Learning from leadership: Investigating the link to improved student learning, Final report of research findings. Wallace Foundation. 
[9] Lundqvist, M., \& Williams Middleton, K. (2013), Academic entrepreneurship revisiteduniversity scientists and venture creation, Journal of Small Business and Enterprise Development, 20, 603-617.10.1108/JSBED-04-2013-0059.

[10] Masa'deh, R., Gharaibeh, A., \& Obeidat, B. (2015), Knowledge Sharing Capability: A Literature Review, in Fourth Scientific \& Research Conference on New Trends in Business, Management and Social Sciences, Istanbul, Turkey, 19-20 September 2015 (pp. 1-16).

[11] Morris, M., Webb, J., Fu, J., \& Singhal, S. (2013), A competency-based perspective on entrepreneurship education: Conceptual and empirical insights, Journal of Small Business Management.

[12] OuYang, Y.-C. (2014), A Cyclic Model for Knowledge Management Capability - A Review Study, Arabian Journal of Business and Management Review, 4 (4), 1-9.

[13] Obeidat, B., \& Abdallah, A. (2014), The Relationships among Human Resource Management Practices, Organizational Commitment, and Knowledge Management Processes: A Structural Equation Modeling Approach, International Journal of Business and Management, 9 (3), 9-26.

[14] Rahimli, A. (2012), Knowledge Management and Competitive Advantage, Information and Knowledge Management, 2(7), 37-43.

[15] Rae, D., Martin, L., Antcliff, V., \& Hannon, P. (2012), Enterprise and entrepreneurship in English higher education: 2010 and beyond, Journal of Small Business and Enterprise Development, 19, 380-401.

[16] Robinson, V., Hohepa, M \& Lloyd C. (2009), School leadership and student outcomes: Identifying what works and why. Best Evidence Synthesis Iteration, Wellington: The University of Auckland and New Zealand Ministry of Education.

[17] Suresh, A. (2012), An Empirical Evaluation of Critical Success Factors of Knowledge Management for Organizational Sustainability, Astitva International Journal of Commerce Management and Social Sciences.

[18] Tony Bush, Derek Glover, (2016), School leadership and management in South Africa: Findings from a systematic literature review, International Journal of Educational Management, Vol. 30 Issue: 2, pp.211-231.

[19] Zaied, A. N., Hussein, G. S. \& Hassan, M. (2012), The Role of Knowledge Management in Enhancing Organizational Performance, International Journal of Information Engineering and Electronic Business, 5(1), 27-35.

[18] Tony Bush, Derek Glover, (2016), School leadership and management in South Africa: Findings from a systematic literature review, International Journal of Educational Management, Vol. 30 Issue: 2, pp.211-231.

[19] Zaied, A. N., Hussein, G. S. \& Hassan, M. (2012), The Role of Knowledge Management in Enhancing Organizational Performance, International Journal of Information Engineering and Electronic Business, 5(1), 27-35. 